\title{
TELETRABALHO DE MULHERES DURANTE A PANDEMIA E O DISCURSO DO FEMINISMO LIBERAL
}

WOMEN IN TELEWORKING DURING THE PANDEMIC AND THE DISCOURSE OF LIBERAL FEMINISM

\author{
Samia Moda Cirino ${ }^{1}$ \\ Faculdades Londrina \\ "Quantas vezes você saiu do seu apartamento \\ E chegou no térreo com um prato de alimento \\ Pra tia que tava trampando no sinal \\ Pra sustentar os quatro filhos que já tá passando mal de \\ fome? \\ Quantas vezes cê parou pra perguntar o nome \\ E pra falar sobre seu ativismo? \\ Quando foi que cê pisou numa favela pra falar sobre o seu \\ Fe-mi-nis-mo? \\ Sempre deixando pra amanhã \\ Deixando pra amanhã \\ Há miliano que cês tão queimando sutiã..." \\ (Musica de Bia Ferreira. De dentro do Ap).
}

\begin{abstract}
Resumo:
O presente trabalho analisa o teletrabalho realizado por mulheres durante a pandemia, haja vista a discussão quanto ao acúmulo de atividades produtivas e reprodutivas durante esse período de forma mais expressiva por elas. Esse problema nos remete à análise da divisão sexual do trabalho de acordo com diferentes vertentes dos feminismos, especialmente o Feminismo Liberal, eis que é com base nessa perspectiva que os trabalhos produtivo e reprodutivo têm sido veiculados nas mídias. Após a coleta de dados estatísticos sobre o trabalho das mulheres durante a pandemia e do levantamento bibliográfico sobre o tema, foi possível verificar que o discurso de mulheres quanto ao acúmulo de atividades reprodutivas e produtivas durante pandemia mascara um conteúdo racial e excludente fomentado pelo Feminismo Liberal no contexto do capitalismo neoliberal. Ao contrapor esse discurso com perspectivas críticas do Feminismo Radical e Marxista, concluiu-se que, para uma parte das mulheres, o acúmulo das atividades de reprodução social durante o período de pandemia, em grande medida, decorre da dispensa de trabalhadoras domésticas ou, ainda, da impossibilidade dessas trabalhadoras laborarem durante esse período devido à falta de políticas públicas de apoio durante a crise de saúde.
\end{abstract}

Palavras-chave:

Feminismos. Divisão sexual do trabalho. Teletrabalho. Reprodução social. Crise de cuidado.

\begin{abstract}
:
This paper analyzes teleworking realized by women during the pandemic, in view of the discussion regarding the accumulation of productive and reproductive activities during this period in a more expressive way by them. This problem leads us to the analysis of the sexual division of labor according to different aspects of feminisms, especially Liberal Feminism, because it is based on this perspective that productive and reproductive work has
\end{abstract}

\footnotetext{
${ }^{1}$ Doutora em Direito pela Universidade Federal do Paraná (UFPR) na linha de Direitos Humanos e Democracia. Mestre em Direito e Bacharel em Direito pela Universidade Estadual de Londrina (UEL). Professora no Programa de Mestrado Profissional em Direito das Faculdades Londrina e no Curso de Graduação em Direito das Faculdades Londrina. Professora na Pós-Graduação em Direito do Instituto de Direito Constitucional e Cidadania (IDCC). Pesquisadora do Grupo de Pesquisa Liberdades em Disputa (LED) da Universidade Estadual de Londrina (UEL) e do Grupo de Pesquisa Sexualidade, Direito e Democracia da Universidade Federal Fluminense (UFF). E-mail: samiamoda@hotmail.com
} 
been diffuse in the media. After collecting statistical data about the work of women during the pandemic and collecting the bibliography on the topic, it was possible to verify that the discourse of women regarding the accumulation of reproductive and productive activities during the pandemic masks a racial and exclusionary content fomented by Liberal Feminism in the context of neoliberal capitalism. By opposing this discourse with critical perspectives of Radical and Marxist Feminism, it was concluded that, for a part of women, the accumulation of social reproduction activities during the pandemic period, to a large extent, results from the dismissal of domestic workers, or, still, from the impossibility of them to work during this period due to the absence of public support policies during the health crisis.

Key words:

Feminisms. Sexual division of labor. Teleworking. Social reproduction. Crisis of care.

\section{INTRODUÇÃO}

Em decorrência do estado de calamidade pública decorrente do COVID-19 (DecretoLegislativo 6/2020) desde 2020 verificamos a determinação por parte das autoridades estatais de suspensão temporária ou a redução dos horários de atendimento ao público de atividades econômicas consideradas como não essenciais. Ainda, mesmo para as atividades consideradas essenciais, existe a orientação de se adotarem medidas sanitárias nos locais de trabalho para evitar a exposição de trabalhadores à contaminação, especialmente de pessoas consideradas do grupo de risco. Obviamente, todas essas medidas sanitárias acabam por repercutir diretamente nos trabalhadores, por isso, paralelamente a essas medidas sanitárias, também foram editadas medidas normativas para flexibilização de direitos trabalhistas nesse período, como a Lei 13.979/2020 e as Medidas Provisórias 927/2020 e 936/2020, esta última, convertida na Lei 14.020/2020, e mais recentemente as Medidas Provisórias 1.045/2021 e 1.046/2021.

Entre as medidas normativas indicadas para esse período, vemos, por exemplo, que a MP 927/2020 dispunha sobre a possibilidade de o empregador, unilateralmente, alterar o regime de trabalho de seus empregados(as) para teletrabalho (art. $4^{\circ}$ ). Embora a referida Medida Provisória não tenha sido convertida em lei, a situação da pandemia persiste e, portanto, a necessidade de adaptar o trabalho presencial ao trabalho à distância como medida preventiva e de combate a COVID-19, como, aliás, dispôs a MP 1.046 de 27 de abril de 2021.

Importante exemplo de adoção do teletrabalho durante a pandemia refere-se à Nota Técnica 01/2020 do Ministério Público do Trabalho (MPT), ao estabelecer como medida para proteção de trabalhadoras gestantes durante o período de crise de saúde pública a alteração do sistema de trabalho presencial para teletrabalho, quando compatível com as suas funções. Posteriormente à referida Nota Técnica, em 12/05/2021, foi publicada a Lei 14.151/2021 que dispõe justamente sobre o afastamento da gestante para exercer trabalho à distância durante a crise de saúde pública decorrente do coronavírus. Da mesma forma, o teletrabalho tem se apresentado como medida adequada para os casos de demais trabalhadores em grupo de risco, 
relacionados, por exemplo, à idade elevada, baixa imunidade e doenças crônicas préexistentes ${ }^{2}$.

Assim, diante do uso intensivo do teletrabalho durante esse período, o presente artigo, inicialmente, analisa as características desse trabalho, suas condições e seu regramento jurídico. Essas compreensões são necessárias também como forma de elucidar os rumos da exploração do trabalho humano no capitalismo da Quarta Revolução Industrial. Isso porque os avanços tecnológicos, que viabilizam essa modalidade de trabalho, somados à experiência agregada nesse período de mais de um ano pandemia, apontam uma tendência para novas formas de exploração do trabalho humano, principalmente se considerarmos as vantagens econômicas agregadas para o empregador na modalidade de teletrabalho, conforme será abordado ao longo da primeira seção deste artigo.

Feitos esses esclarecimentos, a pesquisa desenvolvida volta-se a um grupo específico de pessoas nessa modalidade de trabalho: as mulheres. Esse recorte deve-se ao fato de os dados estatísticos indicarem que cresceu consideravelmente durante a pandemia o número de horas que as mulheres dedicam às atividades domésticas e de cuidados, cumulativamente à atividade produtiva.

Ora, não é novidade que as mulheres acumulam o trabalho produtivo, remunerado, com as atividades domésticas e de cuidados, fruto da divisão sexual das ocupações na nossa sociedade. Nesse sentido, dados do $\operatorname{IBGE}^{3}$ apontam que, em 2019, as mulheres despendiam quase o dobro de tempo que os homens, uma vez que elas, em média, dedicaram 21,4 horas semanais aos afazeres domésticos e de cuidados, enquanto eles dedicaram cerca de 11 horas semanais. Ainda, esse estudo aponta que as mulheres representam o maior contingente em trabalho parcial, sendo $29,6 \%$ entre elas e 15,6\% entre os homens, o que também indica que a opção por essa modalidade de trabalho precário decorre, em certa medida, das atividades domésticas e de cuidados realizadas essencialmente pelas mulheres.

Além disso, se verificarmos dentro do próprio grupo de mulheres, os indicadores de gênero do $\mathrm{IBGE}^{4}$ apontam que, em 2019, as mulheres negras ou pardas estavam mais envolvidas com os afazeres domésticos e de cuidados, representando 22 horas semanais,

\footnotetext{
2 Vide as pessoas em grupo de risco no endereço eletrônico da Organização Mundial da Saúde: https://www.paho.org/pt/covid19. Acesso em 31/03/2021.

3 Dados disponíveis em: https://agenciadenoticias.ibge.gov.br/agencia-sala-de-imprensa/2013-agencia-denoticias/releases/30172-estatisticas-de-genero-ocupacao-das-mulheres-e-menor-em-lares-com-criancas-de-atetres-anos. Acesso em 01/04/2021.

4 Dados disponíveis em: https://agenciadenoticias.ibge.gov.br/agencia-sala-de-imprensa/2013-agencia-denoticias/releases/30172-estatisticas-de-genero-ocupacao-das-mulheres-e-menor-em-lares-com-criancas-de-atetres-anos. Acesso em 01/04/2021.
} 
comparativamente às mulheres brancas (20,7 horas semanais). Considerando também um recorte de classe nesse mesmo período, as mulheres que fazem parte dos $20 \%$ com menores rendimentos trabalharam cerca de 24,1 horas semanais nas atividades de cuidados e afazeres domésticos, enquanto entre as mulheres que se encontram nos $20 \%$ com maiores rendimentos a média foi de 18,2 horas nessas atividades ${ }^{5}$.

Os referidos dados evidenciam as desigualdades de gênero, classe e raça antes mesmo da pandemia, portanto, não é novidade que as mulheres já acumulavam muito mais horas de atividades domésticas e de cuidados em detrimento dos homens, situação agravada conforme são considerados os aspectos de classe e raça. Porém, nesse período de pandemia, o que se verificou é o aumento do contingente de mulheres que se dedicam a essas duas atividades, bem como a intensificação do número de horas que as mulheres passam a se dedicar ao trabalho reprodutivo não remunerado.

Os dados de pesquisa realizada pela Sempre Viva Organização Feminista (SOF) mostram que $50,0 \%$ das mulheres brasileiras passaram a cuidar de alguém ao longo da pandemia. Do total daquelas responsáveis pelo cuidado, $42 \%$ o fazem sem apoio de alguém de fora do núcleo familiar. Ainda, as mulheres negras declararam ter menos apoio externo (54\% dos casos). Entre aquelas que possuem apoio externo (32,4\%), as negras (55,5\%) são maioria entre as que buscam esse apoio entre redes de relacionamento mais próximas, como parentes e vizinhos, ao passo que as mulheres brancas $(52,4 \%)$ são maioria nas que contam com apoio institucionalizado (creches e casas de idosos) ${ }^{6}$.

Tal circunstância pode ser associada a uma série de fatores, como o fechamento de escolas no período de pandemia, o que levou as crianças a ficarem em casa, transferindo o trabalho outrora realizado por educadoras e professoras às mulheres dentro do âmbito domiciliar. Agrega-se a isso o fato de as mulheres serem as principais responsáveis pelo cuidado com pessoas idosas e enfermas, o que foi agravado diante do cenário de pandemia, haja vista a limitação dessas pessoas, até mesmo, para atividades básicas no intuito de evitar a contaminação.

Mas, outra hipótese a ser considerada e sobre a qual se lança uma reflexão crítica, principalmente ao considerarmos a estrutura ocupacional no Brasil e a bipolarização das atividades das mulheres, decorre da observação de que a apontada sobrecarga das mulheres de

5 Dados disponíveis em: https://agenciadenoticias.ibge.gov.br/agencia-sala-de-imprensa/2013-agencia-denoticias/releases/30172-estatisticas-de-genero-ocupacao-das-mulheres-e-menor-em-lares-com-criancas-de-atetres-anos. Acesso em 01/04/2021.

${ }^{6}$ Dados disponíveis em https://cebrap.org.br/wp-content/uploads/2021/02/Informativo-7-Desigualdades-raciais-ede-ge\%CC\%82nero-no-mercado-de-trabalho-em-meio-a\%CC\%80-pandemia.pdf. Acesso em 01/04/2021. 
classe média e alta nesse período decorre, por um lado, da dispensa de diaristas ou empregadas domésticas, pelo impacto econômico da pandemia no orçamento familiar. Outra hipótese decorre da constatação da impossibilidade de as trabalhadoras domésticas comparecerem ao trabalho por ausência de políticas públicas que viabilizem seu transporte, sem risco de contaminação, até os locais de trabalho, bem como das próprias condições de trabalho nas residências, com pessoas contaminadas ou suspeitas de contaminação. Acrescente-se a ausência de suporte para o cuidado de filhos(as) e familiares dessas trabalhadoras domésticas durante a jornada de trabalho. É importante registrar que, no Brasil, o primeiro caso oficial de morte por COVID-19 foi de uma empregada doméstica ${ }^{7}$.

Diante disso, propõe-se outro olhar sobre o problema de acúmulo de atividades produtivas e reprodutivas durante a pandemia que agregue ao aspecto de gênero a opressão e exploração decorrente de raça e classe. Assim, o presente trabalho lança a seguinte reflexão: a propagada denúncia pelas mulheres, principalmente das classes mais abastadas no Brasil, na mídia e redes sociais, de acúmulo de tarefas produtivas e reprodutivas durante a pandemia, deve-se a um despertar da consciência feminista dessas mulheres quanto à divisão sexual do trabalho, ou a um discurso equivocado de igualdade fundamentado no Feminismo Liberal?

Para responder essa questão são identificadas as principais características dessa perspectiva dos feminismos e seus desdobramentos no capitalismo sob a égide neoliberal. Posteriormente, esse pensamento é enfrentado de forma crítica, principalmente a partir do pensamento do Feminismo Radical e do referencial teórico de Nancy Fraser. Intenta-se verificar se as pautas de reivindicação e pensamento do Feminismo Liberal viabilizam esse despertar de uma consciência feminista e, consequentemente, a emancipação das mulheres, ou se acaba por confirmar a lógica opressora das relações de gênero.

\section{TELETRABAlHo E SEU DESViRTUAMENTO JURÍDiCo DURANTE A PANDEMIA}

Durante o período de pandemia verificou-se um aumento significativo de pessoas em situação de teletrabalho como medida sanitária para evitar o contágio e disseminação da COVID-19. Contudo, um olhar mais atento sobre a forma como esse trabalho à distância tem sido exigido por parte de empregadores nesse período traz a necessidade de investigar se

\footnotetext{
7 Vide, por exemplo, notícia em: https:/g1.globo.com/rj/rio-de-janeiro/noticia/2020/09/17/seis-meses-aposdomestica-ser-a-1a-a-morrer-de-covid-no-rj-outras-profissionais-relatam-desafios-na-pandemia.ghtml. Acesso em 03/04/2021.
} 
realmente esses trabalhadores, em termos jurídicos, estão sendo submetidos ao regime legal de teletrabalho, ou se houve apenas transferência simbólica do trabalho realizado antes no estabelecimento da empresa para o âmbito residencial.

Uma causa importante do apontado desvirtuamento das características legais do teletrabalho consiste na confusão quanto à definição e delimitação dessa modalidade de trabalho e, portanto, em sua diferenciação quanto a outras modalidades de trabalho à distância. Ora, é notório que os avanços tecnológicos no capitalismo da era da informação e conhecimento permitiram novas modalidades de exploração do trabalho humano, viabilizando, por meio da internet, que o(a) empregado(a) labore em qualquer local conectado à rede ou plataforma da empresa. Assim, o trabalho à distância, em si, não é novidade nas relações de emprego, tanto é que a CLT já contemplava no seu art. $6^{\circ}$ que "não se distingue entre o trabalho realizado no estabelecimento do empregador, o executado no domicílio do empregado e o realizado a distância, desde que estejam caracterizados os pressupostos da relação de emprego".

A questão principal é que não será todo o trabalho realizado à distância, portanto, fora do estabelecimento da empresa, que poderá ser considerado teletrabalho. Nesse sentido, notese que o art. 75-B da CLT aduz expressamente que não caracteriza teletrabalho aquele que, por sua natureza, constitua trabalho externo. Isso já nos dá a ideia de que a principal característica do teletrabalho não reside no fato de ser realizado fora da empresa, eis que outras ocupações realizam atividade externamente (como instaladores, vendedores externos, montadores, motoristas etc.). Nesses termos, infere-se da referida norma que a característica essencial do teletrabalho é ser realizado à distância em razão do emprego de tecnologias da informação e comunicação, como a internet. Ou seja, independentemente do local onde estiver o(a) empregado(a), conseguirá ter acesso à rede e plataforma virtual da empresa para realizar suas atividades laborais.

A partir disso, outra questão que se levanta é: o local onde o(a) empregado(a) se conecta e realiza o trabalho à distância altera a caracterização do teletrabalho? Tal questionamento devese ao fato de o trabalho à distância poder ser realizado na residência do(a) empregado(a), em estações da empresa situadas em diversas cidades, em espaços de coworking, entre outros. A respeito do local onde o trabalho à distância é realizado, note-se a inserção como teletrabalho das atividades realizadas nos seguintes locais, consoante descrição de Denise Pires Fincato e Amanda Scotá de Andrade (2018, p. 286): 
desenvolvido em telecentros comunitários, que são ambientes com disposição de equipamentos necessários para o desenvolvimento do trabalho em locais que possuem instalações adequadas - maneira de facilitar para o teletrabalhador, que não precisa ir até a sede da empresa e não precisa possuir em sua residência a estrutura que o regime do teletrabalho demanda (HERNANDEZ, 2011, p. 38) - ou, ainda, em centros satélites, espécies do gênero telecentro, que são mantidos pela própria empresa empregadora, não se constituindo tais espaços, entretanto, em sedes ou filiais, de forma que o teletrabalhador possa manter comunicação eletrônica constante e direta com o empregador (COLNAGO, 2017, p. 89).

Não obstante a ausência de consenso quanto ao tema, verifica-se que, a depender do local onde o empregado realiza o trabalho à distância, existe a tendência de se denominar de home office, trabalho remoto ou teletrabalho. Essa ausência de consenso pode ser verificada também na Lei 14.151/2021, que, ao prever o direito de afastamento da gestante do trabalho presencial durante a pandemia, estipulou no seu art. $1^{\circ}$, parágrafo único, que "a empregada afastada nos termos do caput deste artigo ficara à disposição para exercer as atividades em seu domicílio, por meio de teletrabalho, trabalho remoto ou outra forma de trabalho à distância".

Especialmente durante a pandemia, verifica-se a veiculação de notícias sobre home office, assim delimitado como espécie de teletrabalho que é realizado em âmbito residencial. Ou seja, a lógica aparente é a de que trabalhar em casa por meio de redes de comunicação e informação caracteriza espécie de teletrabalho e, portanto, todo o regramento jurídico previsto no capítulo II-A da CLT, como a ausência de direitos relativos à duração da jornada, seria aplicável ao home office. A esse respeito, um Manual de Teletrabalho elaborado pelo Tribunal Superior do Trabalho (TST), em 2020, estabelece que:

[...] teletrabalho é um termo mais abrangente, que inclui o trabalho realizado em casa ou em outros locais que não sejam a empresa - em espaços de coworking, cafeterias, etc. Já o home office é um termo específico ao trabalho realizado em casa, abrangendo também trabalhadores autônomos e freelancers ${ }^{8}$.

Ainda, especificamente sobre o trabalho fora do ambiente da empresa, dispõe a Convenção 177 da Organização Internacional do Trabalho - OIT (não ratificada pelo Brasil):

(a) la expresión trabajo a domicilio significa el trabajo que una persona, designada como trabajador a domicilio, realiza:

(i) en su domicilio o en otros locales que escoja, distintos de los locales de trabajo del empleador;

(ii) a cambio de una remuneración;

(iii) con el fin de elaborar un producto o prestar un servicio conforme a las especificaciones del empleador, independientemente de quién proporcione el equipo, los materiales u otros elementos utilizados para ello, a menos que esa persona tenga

\footnotetext{
${ }^{8}$ Manual Educativo produzido pelo TST, disponível em: https://www.conjur.com.br/dl/manual-teletrabalho.pdf. Acesso em 01/04/2021.
} 
el grado de autonomía y de independencia económica necesario para ser considerada como trabajador independiente en virtud de la legislación nacional o de decisiones judiciales;

(b) una persona que tenga la condición de asalariado no se considerará trabajador a domicilio a los efectos del presente Convenio por el mero hecho de realizar ocasionalmente su trabajo como asalariado en su domicilio, en vez de realizarlo en su lugar de trabajo habitual;

Contudo, tratando-se de relação de emprego, entendemos que a caracterização do teletrabalho não deve ocorrer pelo simples local da realização do trabalho à distância, mas sob o enfoque de como esse trabalho é explorado pelo empregador. Afinal, trabalho no capitalismo é a força de trabalho vendida como mercadoria por meio do contrato de trabalho em troca do salário para subsistência. Essa perspectiva é necessária, considerando que no nosso sistema normativo o teletrabalho implica, por um lado, o não reconhecimento de alguns direitos trabalhistas, a exemplo dos já mencionados direitos relacionados à jornada (horas extras, intervalos intrajornada e interjornada, trabalho noturno, trabalho em domingos e feriados etc.), o que, consequentemente, tem efeitos consideráveis na remuneração do(a) empregado(a). A exclusão desses direitos relativos à jornada para os(as) empregados(as) em teletrabalho está prevista expressamente no art. 62, III, da CLT.

Mas, não apenas isso, o teletrabalho acaba por inverter o requisito da alteridade nas relações de emprego, ou seja, de que os custos da atividade econômica correm por conta do empregador. Afirma-se tal, pois, nos termos do art. 75-D da CLT, não há obrigação legal de o empregador arcar ou ressarcir o(a) empregado(a) com os custos de equipamentos e infraestrutura necessária à prestação do teletrabalho, devendo haver previsão expressa sobre essa obrigação no contrato ou termo de adesão ao contrato de trabalho que estipula o sistema de teletrabalho:

Art. 75-D - As disposições relativas à responsabilidade pela aquisição, manutenção ou fornecimento dos equipamentos tecnológicos e da infraestrutura necessária e adequada à prestação do trabalho remoto, bem como ao reembolso de despesas arcadas pelo empregado, serão previstas em contrato escrito.

Tal sistemática, além de possibilitar, indevidamente, a transferência dos custos da atividade econômica ao(à) empregado(a), parece desconsiderar que a responsabilidade quanto a esses custos não pode ficar no âmbito da autonomia da vontade das partes, haja vista o princípio da hipossuficiência que rege as relações de emprego. Ao viabilizar a transferência desses custos, como consequência lógica, haverá impactos na remuneração do(a) empregado(a), uma vez que essa espécie de trabalho implica gastos com internet, equipamentos e sua manutenção, energia elétrica, entre outros. 
Assim, se a realização do teletrabalho implica a ausência de reconhecimento de alguns direitos trabalhistas, no caso concreto, seus limites legais deverão ser estritamente observados, sob pena de descaracterização desse sistema de trabalho e, consequentemente, o reconhecimento do sistema normal de trabalho, nos termos do art. $6^{\circ}$ da CLT. Portanto, se uma das consequências dos(as) empregados(as) em teletrabalho consiste na ausência de direitos relativos à duração da jornada, entende-se incompatível com esse sistema de trabalho a exigência do cumprimento de horários de trabalho. Ou seja, a tendência que se tem verificado durante a pandemia, de exigir que os(as) empregados(as) estejam logados no sistema da empresa nos mesmos horários de entrada e saída do trabalho presencial, desvirtua a situação de teletrabalho, pois, nesse caso, haverá o controle de jornada por parte do empregador. Consequentemente, não pode o empregador, sob o título de teletrabalho, colocar o(a) empregado(a) para laborar à distância, controlando e exigindo o cumprimento de horários de trabalho, sem quitar os correspondentes direitos à jornada, pois, à luz do art. $9^{\circ}$ da CLT, tratase de fraude para mascar direitos trabalhistas. Sobre as diversas formas de controlar o teletrabalho, ressaltam Rodolfo Pamplona Filho e Leandro Fernadez (2018, p. 61):

\begin{abstract}
Em verdade, é de conhecimento geral a existência de inúmeros programas e aplicativos concebidos precisamente para o controle da duração do labor do empregado no sistema de teletrabalho, mediante, por exemplo, a programação do tempo médio para o cumprimento de cada tarefa ou projeto, com a criação de rotinas de trabalho, o acompanhamento dos períodos de login e logout, o envio de relatórios das atividades desempenhadas, o encaminhamento de mensagens online para acompanhamento das tarefas e fornecimento de feedback, a identificação instantânea da visualização de mensagens, o monitoramento em tempo real do trabalho que está sendo executado pelo obreiro, até mesmo com visualização da imagem em seu monitor e do conteúdo do texto digitado pelo empregado.
\end{abstract}

O que se intenta afirmar é que uma característica essencial do teletrabalho é o fato de o(a) empregado(a) ter liberdade de laborar nos horários que considerar adequados, sem qualquer forma de controle de jornada. Isso porque, a ausência de reconhecimento de direitos trabalhistas relativos à jornada traz, como contrapartida, a liberdade do(a) empregado(a) no que tange aos horários de trabalho. Assim, concluem Pamplona e Fernandez (2018, p. 61), ao afirmar que se for possível, no plano fático, o controle da jornada do(a) empregado(a) em regime de teletrabalho será alcançado pela disciplina celetista da duração do trabalho.

Isso não significa a ausência de controle quanto à subordinação, pois é inerente ao teletrabalho a observância de metas, produtividade, modo de realização do trabalho, características do poder diretivo do empregador. Igualmente, o fato de o(a) empregado(a), eventualmente, ter que comparecer no estabelecimento da empresa, ou de ter que participar de 
reuniões virtuais, não descaracteriza esse regime, desde que, conforme melhor interpretação do disposto no art. 75-B, parágrafo único, da CLT, tal circunstância não seja corriqueira, caracterizando trabalho em sistema híbrido (situação que se enquadra, por exemplo, na previsão contida no art. $74, \S 4^{\circ}$, da CLT).

De acordo com esse raciocínio, o chamado home office, no qual existe controle de jornada, não pode ser entendido como modalidade de teletrabalho, mas tão somente como modalidade de trabalho à distância realizado essencialmente na casa do(a) empregado(a), que, à luz da disposição contida no art. $6^{\circ}$ da CLT, não afasta os direitos relativos à duração da jornada. Note-se que aqui não nos referimos ao home office como trabalho à domicilio, que não envolve o uso de sistemas telemáticos. Nesse sentido, esclarecem Daniela Favilla de Almeida e Lorena de Mello Rezende Colnago (2016, p.117):

\begin{abstract}
O trabalho em domicílio é aquele desenvolvido na residência do empregado, sendo uma modalidade de trabalho à distância mais restrita sob a óptica do local de trabalho, enquanto o teletrabalho ou trabalho desenvolvido por meios telemáticos é uma forma de exercício das funções cotidianas laborais em qualquer lugar do globo terrestre que permita uma conexão com a Internet e o acesso aos meios de comunicação telemáticos - celular, rádio, pager, bip, Skype, WhatsApp, e-mail, dentre outros que ainda podem surgir.
\end{abstract}

Convém, ainda, diferenciar o teletrabalho do trabalho remoto. Embora a legislação coloque expressamente o teletrabalho como sinônimo de trabalho remoto (art. 75-D, da CLT), acreditamos que a diferenciação se faz necessária, considerando as possibilidades de exploração do trabalho humano na modalidade à distância. Nessa lógica, o trabalho remoto diferencia-se do teletrabalho por ser o trabalho à distância realizado em estações ou estabelecimentos da empresa em outras localidades, permitindo que o(a) empregado(a) labore em cidade diversa do local da contratação ou da prestação dos serviços. Por ser realizado em ambiente da empregadora, essa situação não pode ser equiparada ao teletrabalho, pois, nesse caso, consideramos que o(a) empregado(a) em trabalho remoto não estará excluído do regime de duração de jornada, haja vista a efetiva possibilidade de controle da jornada (art. 74, caput, da CLT).

Como resultado dessas análises, podemos concluir que, no Direito do Trabalho, o gênero é o trabalho à distância, o qual pode, ou não, ser realizado por meio do uso de sistemas de comunicação e informação. O trabalho à distância realizado com o uso de ferramentas telemáticas, por sua vez, compreende: i) o teletrabalho, que pode ser realizado em qualquer lugar e sem qualquer forma de controle de jornada, ficando, portanto, na discricionariedade do(a) empregado(a) os horários e local de trabalho; ii) home office, o qual implica o trabalho 
realizado essencialmente na residência do(a) empregado(a), mediante controle dos horários de trabalho; iii) trabalho remoto, que se caracteriza por ser realizado em estações ou estabelecimentos da empregadora fora do local da contratação ou da prestação dos serviços, submetendo-se, dessa forma, ao controle de jornada.

Feitos esses esclarecimentos, é necessário realizar um recorte de gênero sobre o tema, haja vista que os dados estatísticos apontam que o maior contingente de pessoas em teletrabalho durante a pandemia é de mulheres.

\section{A DIVISÃO SEXUAL DO TRABALHO E O FEMINISMO LIBERAL}

Para as mulheres, principalmente durante a pandemia, o teletrabalho não envolve apenas a discussão quanto às consequências jurídicas dessa modalidade de trabalho à distância, mas, igualmente, o acúmulo dessa atividade produtiva com os afazeres domésticos e de cuidados, ou seja, com as atividades de reprodução social. Obviamente que esse problema de acúmulo de atividades produtivas e não produtivas pelas mulheres não é característica exclusiva desse período de crise de saúde pública. Ocorre, contudo, que nesse período o número de mulheres colocadas em situação de teletrabalho aumentou, bem como aumentou o número de horas que as mulheres se dedicam às atividades domésticas e de cuidados. Por isso, é necessário compreender a lógica que orienta essa atribuição de atividades reprodutivas quase que exclusivamente às mulheres, bem como as formas de abordagem desse problema pelos feminismos. A compreensão dessa lógica e a reflexão crítica sobre as formas de enfrentamento pelas vertentes teóricas dos feminismos possibilitarão verificar se os discursos nas mídias e redes sociais que denunciam o acúmulo de atividades domésticas e de cuidados pelas mulheres durante a pandemia decorrem de uma tomada de consciência quanto à importância de se identificar com os feminismos ou se é uma apropriação indevida da crítica feminista.

A atribuição essencialmente às mulheres das atividades domésticas e de cuidados, consideradas reprodutivas e, portanto, não remuneradas, não decorre de uma questão feminina inata, mas é proposital, engendrada nos interesses do capitalismo. Não se pretende afirmar com tal premissa que a gênese da opressão e exploração das mulheres se deu no capitalismo, mas que a discriminação de gênero no capitalismo é uma condição sistêmica. O modelo específico de opressão sexista das sociedades capitalistas consistiu em "separar a produção de pessoas da obtenção de lucro, atribuir o primeiro trabalho às mulheres e subordiná-lo ao segundo" (ARRUZZA et al, 2019, p. 51). Ou seja, o capitalismo promoveu uma bem sucedida divisão das ocupações em atividades produtivas, remuneradas, e atividades reprodutivas, não 
remuneradas, por meio de uma norma estruturante fundamental consistente na divisão sexual do trabalho. Assim, embora a estrutura ocupacional em cada país possa variar, de acordo com aspectos como centralidade e periferia, existe uma lógica comum no capitalismo que, especificamente no que tange ao gênero, distribui as forças produtivas e também reprodutivas da mão de obra.

Ora, o capitalismo, como sistema social e econômico, não envolve apenas a produção de bens e serviços, mas, igualmente, a reprodução da própria força de trabalho, esta última destinada às mulheres sob um discurso biologizante. Assim, é possível afirmar que o capitalismo reintegrou na esfera do comportamento social aceitável para as mulheres "uma forma de sexualidade dócil domesticada instrumental para a reprodução da força de trabalho e pacificação da mão de obra” (FEDERICI, 2019b, p. 68). A atividade de reprodução nas sociedades capitalistas exercida pelas mulheres é vital, pois se trata da atividade de reprodução social, isto é, de criar e manter a vida em sentido biológico, bem como de desenvolver a força de trabalho subordinada nos interesses das elites dominantes. Nesse aspecto, está diretamente relacionada à atividade de perpetuação do sistema, pela substituição de trabalhadores, bem como no processo de constituição dos próprios sujeitos (subjetivação).

Portanto, a divisão sexual do trabalho é a norma que estrutura as relações laborais e as relações sociais no capitalismo por meio de uma articulação complexa a partir do sexo e do gênero tomados estritamente como constructos naturais. Essa divisão sexuada das atividades é construída a partir de uma interpretação da diferença sexual para que as atividades femininas sejam entendidas como derivações biológicas e não como formulações socioculturais, historicamente forjadas. Conforme explica Silvia Federici (2019a, p. 43):

\footnotetext{
O capitalismo tinha que nos convencer de que o trabalho doméstico é uma atividade natural, inevitável e que nos traz plenitude, para que aceitássemos trabalho sem uma remuneração. Por sua vez, a condição não remunerada do trabalho doméstico tem sido a arma mais poderosa no fortalecimento do senso comum de que o trabalho doméstico não é trabalho, impedindo assim que as mulheres lutem contra ele.
}

De acordo com essa perspectiva distributiva da economia política, o gênero aparece como uma diferenciação enraizada na própria estrutura econômica da sociedade. Ou seja, o gênero, alerta Nancy Fraser (2002, p.64), apresenta-se como princípio básico para a organização da divisão sexual do trabalho, pois dá sustentação à divisão fundamental entre trabalho produtivo pago e trabalho doméstico e de cuidados não pago, sendo este último designado como responsabilidade primária das mulheres. Além disso, sob um aspecto cultural, gênero também estrutura a divisão no âmbito do trabalho pago entre atividades essencialmente femininas, 
socialmente menos valorizadas, e as atividades masculinas, com maior reconhecimento e remuneração.

Esse aspecto estruturante da divisão sexual do trabalho também é considerado por Flávia Biroli (2018, p. 44) ao afirmar que "ela não é expressão das escolhas de mulheres e homens, mas constitui estruturas que são ativadas pela responsabilização desigual de umas e outros pelo trabalho doméstico, definindo condições favoráveis à sua reprodução". Com isso, verifica-se que a divisão sexual do trabalho não se trata apenas de uma hierarquização das ocupações e divisão das atividades produtivas (remuneradas) e reprodutivas (não remuneradas), mas envolve um complexo sistema de sexo-gênero e um sistema de relações produtivas que operam simultaneamente para reproduzir as estruturas socioeconômicas.

A denúncia quanto ao caráter sexista da divisão das ocupações e as formas de lutas para superação dessa lógica da reprodução social são objetos dos feminismos há muito tempo, sendo que as estratégias de abordagem e enfrentamento do problema dependem de cada perspectiva dos feminismos. Tal decorre do fato de que os feminismos não estão restritos a uma única etapa, um único movimento, ou uma única teoria, mas encampam uma diversidade de perspectivas e posicionamentos que refletem na luta política de emancipação das mulheres.

Essas linhas teóricas, pautas políticas e movimentos são agrupados nos feminismos em três fases ou ondas dos feminismos. É importante mencionar que as classificações das ondas, quanto às vertentes, perspectivas teóricas e pautas de reivindicações, não são unanimes. Até mesmo porque o término de uma fase não significa que suas pautas foram superadas, mas que essas mesmas pautas apresentam outras perspectivas e desdobramentos, além do que novas pautas e lutas vão sendo agregadas.

Assim, temos do momento histórico que vai do século XIX até a década de 1960 o que se convencionou denominar de primeira onda dos feminismos. Essa fase é comumente identificada com o sufragismo, pois, tomando por base a teoria liberal e democrática de igualdade e liberdade, tinha como principal objetivo a conquista do direito de voto, por meio do qual outros direitos poderiam ser reconhecidos. Contudo, ao longo de todo esse período histórico, o movimento não se restringiu à pauta de conquista do direito de voto, pois envolveu desde o ingresso de mulheres da classe proletária no mercado de trabalho no capitalismo industrial a questionamentos sobre vestimenta, sexualidade, maternidade, educação, salário etc. Fundamentadas nos princípios do liberalismo, dando ensejo ao que se convencionou identificar como Feminismo Liberal, a ideia central dessas lutas envolvia a igualdade entre homens e mulheres. Assim, o principal da visão dos feminismos daquela época era de que mulheres e homens deveriam ser tratados como iguais. 
O desdobramento que o Feminismo Liberal tomou na contemporaneidade é alvo de severas críticas, a exemplo da recente fase da autora Nancy Fraser que juntamente a Cinzia Arruzza e Tithi Bhattacharya (2019, p. 26) consideram que essa vertente dos feminismos foi cooptada como um "serviçal do capitalismo". As autoras (ARRUZZA et al, 2019, p. 26) falam em "dominação com oportunidades iguais" por considerar que as feministas liberais querem "um mundo onde a tarefa de administrar a exploração do local de trabalho e opressão no todo social seja compartilhada igualmente por homens e mulheres da classe dominante”. Ainda, a crítica estende-se à recusa de tratar das restrições socioeconômicas que inviabilizam a liberdade e por se fundamentar, na realidade, na meritocracia, e não na igualdade. Importante crítica também se refere à terceirização da opressão, pois muitas mulheres somente conseguem alcançar determinadas posições na estrutura ocupacional em razão do trabalho doméstico e de cuidados de mulheres de classes menos favorecidas.

Assim, os desdobramentos do Feminismo Liberal continuam mesmo após a década de 1960, quando tem início a segunda onda dos feminismos, haja vista que muitas pautas não foram conquistadas, além do que outras passaram a ser agregadas em face do novo contexto social e político da época. Isso porque essa segunda fase dos feminismos foi, inicialmente, fomentada pelo radicalismo da Nova Esquerda (New Left), quando os feminismos passaram a ser identificados como um dos mais importantes movimentos sociais da década de 1960 que desafiaram as estruturas da social-democracia do pós-guerra. Essa fase estende-se nas décadas de 1960, 1970 e 1980. Em acréscimo às pautas da fase anterior, foram incorporadas questões como as condições de classe e as condições socioeconômicas das mulheres.

Nessa fase, Linda Nicholson (2010, p.5) ressalta que um importante fato foi a institucionalização dos feminismos: a criação de programas de estudos feministas; o estabelecimento de centros e abrigos de vítimas de estupro e violência doméstica; a criação de organizações voltadas às causas das mulheres e a formação de organizações de políticas para as mulheres.

Esse momento histórico continua a abranger as ideais do Feminismo Liberal, mas ganham forças outras correntes dos feminismos, denominado Feminismo Radical, cujo slogan corresponde "o pessoal é político", chamando a atenção para pautas como o trabalho doméstico, violência doméstica e papeis sexuais. A ideia principal era de que a opressão e exploração vivenciadas pelas mulheres no âmbito doméstico fossem discutidas na esfera pública. A respeito desse slogan, bell hooks $(2019$, p. 56) esclarece que foi usado, primeiramente, "para frisar que a realidade cotidiana da mulher é orientada e moldada pela política e possui um 
caráter intrinsecamente político”. Contudo, a autora (hooks, 2019, p. 57) considera que essa espécie de pensamento ensejou a ilusão de que o fato de encorajar as mulheres a pensar sobre a experiência de discriminação, exploração e opressão corresponderia, automaticamente, à formação de uma consciência crítica sobre o aparato ideológico e institucional que determina suas posições e papeis na sociedade. Por isso, hooks (2019, p. 57) alerta que "descrever a própria realidade é um passo significativo no longo processo de autodescoberta, mas compreende apenas o começo da jornada”. A autora (hooks, 2019, p. 57) complementa que “perspectivas mais amplas só podem emergir se examinarmos tanto a dimensão pessoal que é política quanto os aspectos políticos da sociedade como um todo, assim como as políticas orientadas à revolução global".

Diferentemente do Feminismo Liberal, pautado na premissa de igualdade de mulheres e homens, o Feminismo Radical pautou-se na ideia da diferença de homens e mulheres. Ora, igualdade formal não bastava. Mero reconhecimento formal de direitos não bastava, pois, conforme afirma Luis Felipe Miguel (2014, p. 64), a igualdade reivindicada era "entendida como a busca pela inserção numa universalidade que não é neutra - já está preenchida com as características do "masculino"”.

Assim, verificou-se a necessidade de os feminismos incorporarem a luta por políticas públicas de discriminação positiva para efetiva emancipação das mulheres, dando ensejo a o que ficou conhecido como política da diferença. Não bastava inserir as mulheres no mercado de trabalho; era necessário estabelecer garantias para a continuidade da relação de emprego por meio do reconhecimento de direitos, como, por exemplo, estabilidade no emprego da gestante, licença maternidade, creches, entre outros.

Ainda, essa vertente dos feminismos também visava a denunciar o patriarcado como causa da opressão e exploração das mulheres, o que é visto por Céli Regina Jardim Pinto (2010, p. 16) como o que "há de mais original no movimento, que existe uma outra forma de dominação - além da clássica dominação de classe -, a dominação do homem sobre a mulher - e que uma não pode ser representada pela outra, já que cada uma tem suas características próprias".

Nesse período histórico, também é possível identificar as correntes do Feminismo Marxista e Socialista pautadas em questões como racismo, sexismo e classe, ou seja, compreendiam efetivas mudanças na estrutura social. A partir dos estudos de Karl Marx e Friedrich Engels sobre luta de classes agregou-se ao marxismo os estudos de gênero - não em termos do desconstrutivismo, mas de questionamentos iniciais e gerais sobre essa categoria -, denunciando o sistema de reprodução sexista sobre a qual o capitalismo está assentado 
(SCOTT, 1989, p. 11). O foco, portanto, residia justamente em unir as pautas feministas com a luta anticapitalista. Vislumbrou-se como insuperável a emancipação das mulheres sem a ruptura com o sistema social e econômico capitalista.

Um momento significativo nessa fase dos feminismos foi a consolidação do feminismo negro. A falta de visibilidade da condição das mulheres negras nas primeira e segunda ondas dos feminismos ensejou outra perspectiva, a do Feminismo Negro, principalmente a partir dos movimentos sociais do final da década de 1960. Conforme denuncia Djamila Ribeiro (2019, p. 23), havia uma espécie de cegueira e apagamento pelas feministas brancas "em relação às mulheres negras no que diz respeito à perpetuação do racismo e como naquele momento esse fato não era considerado relevante como pauta feminista por elas". A autora (RIBEIRO, 2019, p. 23) acrescenta que "interessava, ali, a conquista de direitos para um grupo específico de mulheres, o que se perpetuou durante muito tempo, mesmo quando mulheres negras começaram a escrever sobre a invisibilidade da mulher negra como categoria política e a denunciar esse apagamento".

A partir de um referencial das políticas de identidade, no período de 1980-1990, tem início a terceira onda dos feminismos. Com o declínio das propostas da Nova Esquerda, principalmente a partir da década de 1980, Fraser (2009, p. 22) considera que os movimentos antieconomicistas da segunda fase dos feminismos foram ressignificados e incorporados a uma nova pauta política que colocou as questões culturais em primeiro plano. A autora desenvolve uma severa crítica às perspectivas identitárias que ganharam destaque nos feminismo na década de 1990, eis que estabeleceram o foco na defesa de uma suposta identidade feminina que, a partir de traços em comum, poderia fortalecer a luta das mulheres.

Sobre o equívoco desse foco dos feminismos em políticas de reconhecimento, Nancy Fraser (2002, p. 71) denuncia que a busca por uma identidade feminina tende a coisificar a feminilidade e obscurecer os eixos transversos da subordinação, uma vez que "recicla estereótipos de gênero dominantes ao promover o separatismo e o politicamente correto". Além disso, continua a autora, esse enfoque na dimensão de reconhecimento obscurece as outras dimensões da injustiça de gênero, ou seja, a dimensão econômica, atrelada à justiça distributiva, e a dimensão política, referente à representatividade na esfera pública.

Em relação a essas mudanças de postura dos feminismos nas décadas de 1980 e 1990, Nancy Fraser (2002, p. 62) não desconsidera que os danos da injustiça de gênero não são meramente econômicos, ou materiais, mas também culturais, portanto, estreitamente ligados à questão do reconhecimento. O problema, ao ver da autora, consistiu no fato de que essa mudança de foco dos feminismos coincidiu com um desdobramento histórico político mais 
amplo: o neoliberalismo. Ou seja, mudaram o foco da crítica de aspectos relacionados à redistribuição para questões de reconhecimento no momento em que a direita aperfeiçoava seu próprio uso estratégico de uma política cultural progressiva para tirar a atenção de sua política de redistribuição regressiva (FRASER, 2007, p. 301).

Assim, descompromissado com as questões de justiça distributiva, o neoliberalismo apropriou-se do foco da crítica feminista nas políticas de identidade para conferir uma igualdade meramente formal às mulheres no mercado de trabalho. $\mathrm{O}$ discurso de empoderamento das mulheres no capitalismo da contemporaneidade, pautado em políticas neoliberais, pode ser representado pelo seguinte quadro paradigmático: em um extremo, encontram-se os empregos femininos das classes médias profissionais, estabelecidos conforme determinados padrões étnicos, androcêntricos e heterossexuais; do outro extremo, há uma multidão de trabalhadoras temporárias, de trabalho parcial, prestadoras de serviços de baixa remuneração, domésticas, trabalhadoras do sexo, migrantes etc.

Diante desse cenário, fica evidente que a apropriação e ressignificação da crítica feminista pelo capitalismo globalizado sob a égide neoliberal foi negativa para o movimento, pois, além de mascarar as várias dimensões imbricadas de injustiça de gênero, ou seja, não meramente de reconhecimento, mas também distributiva e representativa, trouxe ao trabalho feminino uma precariedade com contornos muito específicos. Por isso, Fraser (2020, p. 129) propõe a retomada das pautas da segunda onda dos feminismos, na sua vertente radical e marxista, focando, mais recentemente em demonstrar como as opressões de gênero, raça e classe são imanentes ou estruturais no capitalismo. Nesse intuito, a autora (FRASER, 2020, p. 197) afirma que as lutas feministas devem focar em três critérios: não dominação em torno de linhas de gênero, raça/etnia e classe; sustentabilidade funcional, principalmente nos aspectos de meio ambiente; e democracia. A autora enfatiza sua crítica nesses três critérios, pois considera que são as bases estruturantes do capitalismo, de modo que, se as lutas feministas desconstruírem esses três critérios, o intuito de superação do capitalismo poderá ser alcançado.

A partir do pensamento de Nancy Fraser podemos inferir que, com a apropriação da crítica feminista no capitalismo sob a égide neoliberal, as pautas de reivindicações dos feminismos radical e negro da segunda onda dos feminismos perderam força, ganhando espaço um discurso falacioso de igualdade de gênero a partir da retomada e expansão do Feminismo Liberal. Esse fenômeno acarretou o que Fraser (2020, p. 105) denomina de "crise de cuidado" diante do desmantelamento do Estado de Bem-Estar social sob a égide de políticas neoliberais.

Para entendermos a apontada crise, é preciso relembrar que o capitalismo, em suas diversas conformações, buscou lidar de formas distintas com a questão da reprodução social. 
Por exemplo, Fraser (2020, p. 101) rememora que no capitalismo liberal a produção econômica foi desacoplada da reprodução social, constituindo duas esferas distintas: a da "fábrica" e a da "casa". Como resultado, foi escancarada a contradição sociorreprodutiva do capital (FRASER, 2020, p. 101): a população recém-urbanizada e proletarizada, incluindo mulheres e crianças, alojada em cortiços fétidos e superlotados, era convocada para trabalhos esgotantes, mal remunerados e inseguros, minando as condições necessárias ao sustento das famílias e reposição do trabalho.

Já no modelo capitalista posterior, que Fraser (2020, p. 102) chama de "capitalismo administrado pelo Estado", o poder público passou a assumir algumas responsabilidades pela reposição do trabalho e pela manutenção da vida familiar nos países centrais do capitalismo. Além disso, nos países de capitalismo central, essa fase do capitalismo fundamentou-se na ideia do salário familiar (FRASER, 2020, p. 102), ou seja, de que o homem empregado deve receber o suficiente para sua subsistência e de sua família, permitindo que as mulheres se dediquem integralmente aos(às) filhos(as) e afazeres domésticos. Obviamente que essa não era a realidade de mulheres pobres de países de capitalismo periférico, que sempre tiveram que acumular as atividades produtivas e reprodutivas sem suporte estatal adequado, o que ficou escancarado com as crises do final da década de 1960, que culminaram com o desmantelamento dessa fase do capitalismo.

No modelo do capitalismo atual, denominado por Fraser (2020, p. 104) de "capitalismo financeirizado", já sob os rumos do neoliberalismo, a ideia de salário familiar sucumbiu à ideia da família com dois salários que, na realidade, representou uma forma de retirada de direitos trabalhistas e redução salarial sob o pretexto de que os feminismos deslegitimavam o sustento das mulheres pelo salário familiar e reivindicavam o ingresso massivo no mercado de trabalho. Agora, as mulheres devem trabalhar "fora de casa", pois é impossível manter uma família com o salário de um único trabalhador. Contudo, essa falsa promessa de libertação das mulheres pelo ingresso no mercado de trabalho ocorreu conjuntamente ao desmantelamento de politicas publicas de assistência social, como creches, saúde, educação etc., de modo que o trabalho produtivo dessas mulheres foi acumulado com o trabalho reprodutivo intensificado ante os cortes no serviço público, gerando a mencionada crise de cuidado. Sobre os efeitos dessa pressão, Fraser (2020, p. 105) descreve: visam a transferir a estratégia de cuidados para outros. Há, por exemplo, 'redes globais de cuidado' amplamente discutidas, por meio das quais trabalhadoras dos países do centro que estão com dificuldade, descarregam o trabalho reprodutivo em migrantes de regiões pobres (muitas vezes mulheres racializadas), que deixam as próprias 
família sob os cuidados de mulheres ainda mais pobres, que precisa, por sua vez, fazer o mesmo, e assim por diante. Longe de resolver a 'crise do cuidado', esse arranjo o desloca do Norte global para o Sul global, incluindo os países que eram comunistas, e introduz uma organização dual do trabalho de cuidado, tornado mercadoria para aqueles que podem pagá-lo e privatizado para aqueles que não podem, com alguns nessa segunda categoria realizando trabalho reprodutivo para aqueles na primeira em troca de (baixos) salários.

Vemos que, longe de oferecer uma solução para o problema da discriminação e violência de gênero, o Feminismo Liberal, ressignificado pela ideologia neoliberal, é parte do problema. Conforme ressaltam Fraser, Arruzza e Bhattacharya (2019, p. 37), focado em permitir que "um pequeno número de mulheres privilegiadas escale a hierarquia corporativa e os escalões das Forças Armadas, esse feminismo propõe uma visão de igualdade baseada no mercado, que se harmoniza perfeitamente com o entusiasmo corporativo vigente pela diversidade". Ou seja, em vez de questionar e abolir as hierarquias sociais sexistas, acaba por diversificá-las, em um discurso de multiculturalismo, empoderando "mulheres talentosas para ascender ao topo", de modo que apenas algumas poucas mulheres privilegiadas alcancem cargos e salários iguais aos dos homens de sua própria classe (ARRUZZA et al, 2019, p. 38).

Esse suposto empoderamento se dá à custa da terceirização da opressão de outras mulheres para as atividades domésticas e de cuidados. Isso quer dizer que, ao ocupar esses postos de poder e atividades produtivas socialmente valorizadas, essas mulheres não deixam de ser incumbidas dos afazeres domésticos e de cuidados, contudo, elas acabam por transferir essas atividades socialmente desvalorizadas para mulheres de classe menos abastadas, agregado a um forte aspecto de raça no nosso país. Isso desvela um feminismo insensível à classe e raça, difamando os feminismos aos vincular a nossa causa "ao elitismo e ao individualismo" (ARRUZZA et al, 2019, p. 38). Nesses termos, o Feminismo Liberal parece oferecer o álibi perfeito para o capitalismo neoliberal (ARRUZZA et al, 2019, p. 39):

\footnotetext{
Ocultando políticas regressivas sob uma aura de emancipação, ele permite que as forças que sustentam o capital retratem a si mesmas como progressistas'. Aliado ao sistema financeiro global nos Estados Unidos, ao mesmo tempo que oferece cobertura à islamofobia na Europa, este é o feminismo das fêmeas detentoras de poder: gurus corporativas que pregam 'faça acontecer', burocratas do sexo feminino que impulsionam os ajustes estruturais e o microcrédito no Sul global, politicas profissionais que vestem terninhos e cobram cachês de seis dígitos para dar palestrar para Wall Street.
}

Isso significa que não basta um feminismo que vise a "domesticar" o capitalismo, o que, ao fim, acaba por manter a sua lógica de exploração e opressão. Em vez disso, Fraser (2020, p. 17) propõe superá-lo por meios mais radicais. Isso requer que os feminismos incorporem a 
critica transformadora da reprodução social em sua perspectiva mais ampla, isto é de considerar a reprodução social não apenas como reprodução da força de trabalho, mas também como forma de criação, socialização e subjetivação (horizontes de valores) de seres humanos, como sugere Fraser (2020, p. 48). Assim, o foco de feministas liberais, exclusivos na discriminação, na ideologia e no direito, afirma Fraser (2020, p. 133), não é o melhor caminho para superar o racismo e sexismo estruturantes do sistema capitalista; é necessário também "enfrentar o vínculo persistente no capitalismo entre expropriação e exploração, reprodução e produção". Ou seja, uma mudança radical de ruptura da atual estrutura social se faz necessária.

\section{TELETRABALHO E O TRABALHO DE REPRODUÇÃO SOCIAL DURANTE A PANDEMIA: RESSIGNIFICAÇÃO DA CRÍTICA FEMINISTA}

Verificamos por meio do atual estado da arte dos feminismos que, principalmente a partir da década de 1990, houve uma apropriação indevida das críticas e pautas dos feminismos, pois o capitalismo sob a égide neoliberal retomou a ideia de igualdade formal do Feminismo Liberal, ora, aliado às políticas e movimentos identitários, em torno de um discurso de traços em comum das mulheres característicos de uma suposta identidade feminina. A forte retomada do Feminismo Liberal nesse período histórico do capitalismo, por outro lado, representou a ressignificação da própria crítica e lutas feministas das décadas anteriores, principalmente dos feminismos que envolvem as questões de classe e raça, como o Feminismo Radical e Feminismos Negro, haja vista as políticas sociais regressivas do neoliberalismo.

Essa retomada e crescimento do Feminismo Liberal foram escancarados durante a pandemia do COVID-19, a partir de 2020, haja vista que discursos sobre desigualdade de gênero passaram a dominar a mídia e redes sociais. Os discursos veiculados sobre as questões de gênero nesse período envolvem, entre outros, justamente a denúncia e crítica ao acúmulo de atividades produtivas e reprodutivas, intensificadas e expandidas durante a pandemia. Isso porque, como uma das medidas para contornar a crise de saúde pública, um número expressivo de trabalhadoras tiveram o trabalho presencial alterado para a modalidade de trabalho à distância (em particular, teletrabalho e home office).

Mas, não podemos desconsiderar que a possibilidade de realizar trabalho à distância não se mostra como uma alternativa para todas as trabalhadoras e não devemos nos iludir, pois isso não se deve apenas por um impeditivo da própria natureza da atividade laboral, mas reside em um forte aspecto de classe e raça em nosso país. Nesse sentido, segundo dados do IPEA, divulgados em dezembro de 2020, o perfil de pessoas em teletrabalho durante aquele ano seguiu 
sendo majoritariamente composto por pessoas ocupadas no setor formal, com escolaridade de nível superior completo, do gênero feminino, de cor/raça branca e com idades entre 30 e 39 anos $^{9}$. Segundo esse relatório ${ }^{10}$, em outubro de $2020,56,9 \%$ das pessoas em teletrabalho eram mulheres. Outro recorte importante é o racial, estima-se que, para o mês de outubro de 2020, $65,0 \%$ das pessoas em teletrabalho eram brancas $^{11}$.

Os discursos veiculados por muitas mulheres nas mídias e redes sociais mascaram ou desconsideram esses aspectos de classe e raça, ou seja: quais são realmente as mulheres que podem realizar trabalho à distância durante a pandemia no Brasil? Os dados apontam: mulheres, brancas, jovens, com nível superior, do setor formal. Para essas mulheres, durante a pandemia, foi colocada outra realidade cotidiana, pois passaram a desempenhar, ou tiveram intensificado o outro lado da divisão sexual do trabalho: as atividades domésticas e de cuidados.

Embora essas atividades de reprodução social sempre tenham sido associadas prioritariamente às mulheres, muitas delas contavam com outras profissionais para realizar ou, ao menos, dividir a realização dessas atividades domésticas e de cuidados, como professoras, babás, diaristas, cuidadoras, entre outras profissionais do care. Ou seja, a atividade de reprodução social era terceirizada para outras trabalhadoras precarizadas na estrutura ocupacional, que no nosso país, está alinhada a um forte componente de raça e classe.

Cumpre observar que trabalhadores em âmbito doméstico no Brasil representam cerca de 6,2 milhões de pessoas, entre as quais $93 \%$ são mulheres e, entre elas, $68 \%$ são negras, de acordo com a Pesquisa Nacional por Amostra Domiciliar (Pnad) de 2018, do IBGE, a mais recente a compilar esses números ${ }^{12}$.

Com a pandemia, houve o fechamento de escolas, creches, além do que inviabilizou a atividade de empregadas domésticas ou, até mesmo, acarretou a dispensa dessas trabalhadoras em razão da crise econômica intensificada pela crise de saúde pública. Assim, as atividades anteriormente realizadas por essas profissionais do cuidado tiveram que ser assumidas por esse outro seguimento de mulheres trabalhadoras melhor colocadas na estrutura ocupacional.

https://www.ipea.gov.br/portal/images/stories/PDFs/conjuntura/201217_cc_49_nota_32_teletrabalho.pdf. Acesso em 01/04/2021.

${ }^{10}$ Dados https://www.ipea.gov.br/portal/images/stories/PDFs/conjuntura/201217_cc_49_nota_32_teletrabalho.pdf. Acesso em 01/04/2021.

12 Dados disponíveis em: http://www.generonumero.media/domestica-auxilio-emergencial-emprego/. Acesso em 01/04/2021. 
O aumento do desemprego das trabalhadoras domésticas durante a pandemia é confirmado pelos dados da Pnad Contínua ${ }^{13}$, divulgados em janeiro de 2021. Esse setor foi o segundo mais atingido no país, com queda de $24,2 \%$, o que representa cerca de 1,5 milhão de postos de trabalho doméstico perdidos de setembro a novembro de 2020, na comparação com o mesmo período de 2019. De modo geral, $45 \%$ das empregadas domésticas foram dispensadas em $2020^{14}$.

Segundo dados divulgados pelo IPEA ${ }^{15}$, o trabalho doméstico informal (sem registo em carteira) representava 3,8\% das ocupações em maio de 2020, mas correspondia, nesse período, a 6,9\% de trabalhadores ocupados afastados temporariamente. Ou seja, foi uma categoria significativamente atingida durante a pandemia, eis que o contingente de pessoas ocupadas no trabalho doméstico passou de 4.458 mil, em maio, para 3.946 mil em julho de 2020, uma perda estimada de $11,5 \%$ de postos de trabalho em três meses.

Importante também mencionar que as domésticas foram a segunda classe trabalhadora mais beneficiada no país com o auxilio emergencial ${ }^{16}$. Ao se fazer uma análise por sexo, observou-se que as mulheres corresponderam a 55\% dos beneficiários do Auxílio Emergencial, segundo dados do Ministério da Cidadania ${ }^{17}$.

Esse cenário corrobora a crítica realizada neste trabalho, de acordo com o referencial de Nancy Fraser, de que a ressignificação das pautas dos feminismos da segunda onda pelo neoliberalismo, para inserção em grande escala de mulheres no mercado de trabalho, acarretou a bipolarização da estrutura ocupacional para elas e a terceirização das atividades de reprodução social. Por sua vez, essa espécie de terceirização de atividades reprodutivas acarretou o que Fraser (2020, p. 105) denomina de crise de cuidado, pois, concomitante ao ingresso das mulheres no mercado de trabalho, as políticas públicas assistenciais foram desmanteladas, deixando as trabalhadoras sem suporte para as atividades domésticas e de cuidados, assumidas, quando possível, por trabalhadoras precarizadas, a exemplo do seguimento das empregadas domésticas.

\footnotetext{
${ }^{13}$ Dados disponíveis em: http://www.generonumero.media/domestica-auxilio-emergencial-emprego/. Acesso em 01/04/2021.

${ }^{14}$ Dados disponíveis em: http://www.generonumero.media/domestica-auxilio-emergencial-emprego/. Acesso em $01 / 04 / 2021$.

${ }^{15}$ Dados disponíveis disponíveis em https://www.ipea.gov.br/portal/images/stories/PDFs/nota_tecnica/201110_diest_n_46.pdf._Acesso em 01/04/2021.

${ }^{16}$ Dados disponíveis em: http://www.generonumero.media/domestica-auxilio-emergencial-emprego/. Acesso em 01/04/2021.
${ }^{17}$ Dados
disponíveis em br/servicos/sagi/relatorios/deolhonacidadania_3_2202.pdf. Acesso em 01/04/2021.
} 
Assim, o que a pandemia acirrou foram esses problemas de políticas sociais regressivas no capitalismo neoliberal e a apropriação indevida das criticas feministas por meio da retomada e expansão do Feminismo Liberal. Como decorrência, o que vemos no nosso país nos discursos de muitas mulheres nas redes sociais é que, ora, conseguem ver o acúmulo da atividade produtiva e reprodutiva, mas não entendem as reais causas. Por isso, requerem a reabertura de creches e escolas, mesmo que as professoras não estejam vacinadas. Por essa razão, exigem a presença de diaristas ou empregadas domésticas, mesmo que essas trabalhadoras se exponham em transportes públicos lotados para chegar e voltar do trabalho e não tenham suporte para deixar filhos(as) ou dependentes sob o cuidado de alguém.

Como já afirmamos, em bell hooks (2019, p. 57), apenas a experiência dessas mulheres na pandemia, com acúmulo intensificado de atividades produtivas e reprodutivas, não acarretará uma consciência feminista. Por isso, a importância de desvelar, por meio de críticas e referenciais teóricos feministas subsistentes, como se intentou por meio da presente pesquisa, a realidade por trás dos números e dos relatos de redes sociais.

\section{CONCLUSÃO}

Os dados estatísticos apresentados no presente trabalho evidenciam, de modo geral, que durante a pandemia do COVID-19 houve um aumento da carga das atividades domésticas e de cuidados pelas mulheres cumulativamente à atividade produtiva, ora, na modalidade de teletrabalho. Como realidade social latente, em um contexto global e informatizado, também houve o incremento dos discursos questionando a distribuição desigual das atividades de reprodução social de acordo com o gênero, veiculados, principalmente, por meio das mídias sociais e grupos de aplicativos de celular. Veicula-se que o "empoderamento" das mulheres, pelos avanços dos feminismos, permitiu para aquelas que se intitulam como feministas denunciar esse quadro de exploração da atividade de reprodução social.

Contudo, sempre que nos deparamos com discursos é necessários investigar a lógica que orienta sua veiculação a fim de constatar se realmente é um desdobramento de movimentos sociais emancipatórios, como os feminismos, ou se é o uso estratégico da crítica ressignificada pelas relações de poder opressoras.

Com intento de desvelar essa lógica, primeiramente, foi necessário compreender no que consiste o teletrabalho, suas características e limitações jurídicas. Isso porque a análise das normas jurídicas sobre essa modalidade de trabalho, bem como de algumas teses doutrinárias sobre o tema evidenciam que existe uma tendência de precarização do trabalho humano nesse 
sistema. Afirma-se tal, pois se verificou que, sob o pretexto de colocar como teletrabalho toda a atividade à distância realizada com o uso de instrumentos informatizados, possibilita-se a supressão de direitos trabalhistas, como àqueles referentes à jornada e relativos aos custos da atividade econômica, com impactos diretos na remuneração de trabalhadores. Por isso, o presente trabalho propôs uma classificação do trabalho à distância, distinguindo entre teletrabalho, home office e trabalho remoto, de modo a assegurar os direitos trabalhistas em cada modalidade.

Essa análise do teletrabalho no Brasil também evidenciou que se utiliza dessa modalidade de trabalho como forma de corroborar a divisão sexual do trabalho, eis que o teletrabalho tem sido justificado como melhor forma de compatibilizar às mulheres as atividades produtiva e os afazeres domésticos e de cuidados. Diante dessa tendência de teletrabalho principalmente para as mulheres, somado ao contexto de pandemia, que, como visto, intensificou essa modalidade de trabalho para elas, foi necessário fazer um recorte do tema sob a perspectiva dos feminismos. Intentou-se demonstrar de que modo a lógica da divisão sexual do trabalho atua nas sociedades capitalistas como norma estruturante para estabelecer a divisão da atividade produtiva e da atividade de reprodução social a partir do gênero.

Em seguida, enveredou-se na análise das diferentes perspectivas teóricas dos feminismos, mais especificamente do Feminismo Liberal, com seus desdobramentos no capitalismo neoliberal, para entender se as propostas de enfrentamento do problema por essa vertente dos feminismos permite a superação da divisão sexual do trabalho, ou, ao contrário, confirma a lógica da exploração sexista das ocupações. Comparativamente às teses do Feminismo Racial e Marxista sobre a reprodução social, principalmente com fulcro na teoria crítica desenvolvida por Nancy Fraser, verificou-se que houve uma apropriação indevida da crítica feminista e ressignificação do Feminismo Liberal pelo neoliberalismo que não absolve as mulheres da atividade de reprodução social, mas, tão somente, terceiriza a opressão das mulheres das elites e classe média para as mulheres das classes sociais menos favorecidas, alinhado a um forte componente de raça. Ou seja, as mulheres que se inserem no mercado de trabalho em atividades socialmente valorizadas na estrutura ocupacional, melhor remuneradas, transferem para trabalhadoras domésticas, precarizadas e mal remuneradas, as atividades domésticas e de cuidados. Essas, por sua vez, sem respaldo econômico para contratar outras trabalhadoras e sem o respaldo de políticas públicas, contam apenas com redes de cuidado de outros familiares e vizinhos para poderem acumular atividade produtiva e reprodutiva. Esse ciclo fomenta a apontada crise de cuidado. 
Portanto, é possível concluir que o aventado discurso durante a pandemia, que questiona o acúmulo de atividades produtiva e reprodutiva não decorre de uma tomada de consciência das mulheres que veiculam esse discurso acerca dos feminismos e seu papel radical transformador. Antes, trata-se de veiculação de um Feminismo Liberal ressignificado pelo neoliberalismo para manter as coisas como estão: mantem-se a divisão sexual do trabalho e a bipolarização do trabalho das mulheres, isto é, entre aquelas que podem ou não pagar pelas atividades de cuidado.

É importante frisar que a adesão das mulheres aos feminismos não se dá pelo fato de serem biologicamente iguais, ou por compartilharem algumas experiências essencialmente femininas, mas que o chamado à luta envolve o despertar de uma consciência crítica pela necessidade de superação dos regimes opressores das relações de gênero, classe e raça. Portanto, a atitude é política, radical e revolucionária.

\section{REFERÊNCIAS BIBLIOGRÁFICAS}

ALMEIDA, Daniela Favilla Vaz de; COLNAGO, Lorena de Mello Rezende. O teletrabalho, o direito à desconexão do ambiente de trabalho e os possíveis meios de inibição da prática. Revista de Direito do Trabalho. vol. 169, ano 42. São Paulo: Ed. RT, maio-jun. 2016, p. 113-126.

ARRUZZA, Cinzia; BHATTACHARY, Thiti; FRASER, NANCY. Feminismo para os 99\%: um manifesto. $1^{\text {a }}$ ed. São Paulo: Boitempo, 2019.

BIROLI, Flávia. Gênero e desigualdades: os limites da democracia no Brasil. 1 ed. São Paulo: Boitempo, 2018.

BUTLER, Judith. El marxismo y lo meramente cultural. In New Left Review, $\mathrm{n}^{\mathbf{0}} 2$, mayojunio, 2000, p. 109-121. Disponível em: newleftreview.es/article/download_. Acesso em 09/04/2021.

. Deshacer el genero. Barcelona: Paidós, 2006.

FEDERICI, Silvia. Mulheres e caça às bruxas: da Idade Média aos dias atuais. 1 ed. São Paulo: Boitempo, 2019a.

\section{O ponto zero da revolução: trabalho doméstico, reprodução e luta}

feminista. São Paulo: Elefante, 2019b.

FINCATO, Denise Pires; ANDRADE, Amanda Scotá de. Home office: direitos fundamentais, meio ambiente laboral e reforma trabalhista. In Revista Direito Econômico e

Socioambiental, Curitiba, v. 9, n. 2, maio/ago. 2018, p. 281-300. Disponível em: https://periodicos.pucpr.br/index.php/direitoeconomico/article/view/22123. Acesso em 10/04/2021. 
FRASER, Nancy. Políticas feministas na era do reconhecimento: uma abordagem bidimensional da justiça de gênero. In BRUSCHINI, Cristina e UNBEHAUM, Sandra G. (orgs.). Gênero, democracia e sociedade brasileira. São Paulo: FCC; Ed. 34, 2002, p. 5978.

. O feminismo, o Capitalismo e a Astúcia da História. In Mediações, Londrina, v. 14, n.2, Jul/Dez. 2009, p.11-33. Disponível em: http://www.uel.br/revistas/uel/index.php/mediacoes/article/view/4505. Acesso em $10 / 04 / 2021$.

Mapeando a imaginação feminista: da redistribuição ao reconhecimento e à representação. In Estudos Feministas, Florianópolis, 15(2): 240, maio-agosto/2007, p. 291-307. Disponível em: https://periodicos.ufsc.br/index.php/ref/article/view/S0104026X2007000200002. Acesso em 10/04/2021.

FRASER, Nancy; JAEGGI, Rahel. Capitalismo em debate: uma conversa na teoria crítica. 1.ed. São Paulo: Boitempo, 2020.

hooks, bell. Teoria feminista: da margem ao centro. São Paulo: Perspectiva, 2019.

MIGUEL, Luis Felipe; BIROLI, Flávia. Feminismo e política: uma introdução. 1 ed. São Paulo: Boitempo, 2014.

NICHOLSON, Linda. Feminism in "Waves": Useful Metaphor or Not? In New Politics. Vol. XII, n. 4, Whole Number 48. Disponível em: https://newpol.org/issue_post/feminism-wavesuseful-metaphor-or-not/ . Acesso em 09/04/2021.

PAMPLONA FILHO, Rodolfo; FERNANDEZ, Leandro. Tecnologia da informação e as relações de trabalho no Brasil: o teletrabalho na Lei n. 13.467/17. Revista eletrônica do Tribunal Regional do Trabalho da $6^{\mathbf{a}}$ Região, Recife, PE, n. 44, p. 49-81, 2018. Disponível em: https://juslaboris.tst.jus.br/handle/20.500.12178/162272. Acesso em 10/04/2021.

PINTO, Céli Regina Jardim. Feminismo, História e Poder. Revista de Sociologia Política, Curitiba, v. 18, n. 36, p. 15-23, jun. 2010. Acesso em:

https://revistas.ufpr.br/rsp/article/view/31624/20159. Acesso em 10/04/2021.

RIBEIRO, Djamila. Lugar de fala. São Paulo: Sueli Carneiro; Pólen, 2019.

SAFFIOTI, Heleieth Iara Bongiovani. Rearticulando gênero e classe social. In Uma questão de gênero. COSTA, Albertina de Oliveira; BRUSCHINI, Cristina (Org.). São Paulo: Fundação Carlos Chagas, 1992.

SCOTT, Joan. Gender: a useful category of historical analyses. In Gender and the politics of history. New York, Columbia University Press, 1989. Disponível em: https://www.jstor.org/stable/1864376?seq=1. Acesso em 10/04/2021. 